J. Lake Sci. (湖泊科学), 2005, 17(2): 139-142

ISSN 1003 -5427; E-mail: jlakes@ niglas. ac.cn

Copyright 2005 by Journal of Lake Sciences

\title{
基于遥感技术的太湖近 15 年面积动态变化
}

殷立琼 ${ }^{1,2}$, 江 $^{1}{ }^{1}{ }^{1}$,杨英宝 ${ }^{1,2}$

( 1 : 中国科学院南京地理与湖泊研究所,南京 210008)

(2: 中国科学院研究生院, 北京 100039)

摘 要: 本文利用 80 年代后期以来不同时期的 LANDSAT 卫星遥感图像, 研究了近 15 年太湖的面积变化状况。研究结果 表明: 从 1988 年到 2003 年的 15 年来, 太湖面积共减少 $9.0226 \mathrm{~km}^{2}$, 其中湖泊围剭了 $4.4584 \mathrm{~km}^{2}$, 湖滩地面积 $0.6968 \mathrm{~km}^{2}$, 取土围堰面积 $3.8674 \mathrm{~km}^{2}$.

关键词: 太湖;面积;动态变化;遥感;围层

\section{Dynamic Change of Lake Taihu Area During the Past 15 Years Based on Remote Sensing Technique}

\author{
YIN Liqiong ${ }^{1,2}$, JIANG $\mathrm{Nan}^{1} \&$ YANG Yingbao ${ }^{1,2}$ \\ ( 1 : Nanjing Institute of Geography \& Limnology, Chinese Academy of Sciences, Nanjing 210008, P. R. China) \\ (2: Graduate School of Chinese Academy of Science, Beijing 100039, P. R. China)
}

\begin{abstract}
Based on the LANDSAT remote sensing images since the late 1980s, the area change of Lake Taihu in the recent 15 years was studied. The results showed that of $9.0226 \mathrm{~km}^{2}$ the lake area had collectively declined from 1988 to $2003,4.4584,0.6968$ and $3.8674 \mathrm{~km}^{2}$ of which were due to reclamation, bottomland and cofferdam respectively.
\end{abstract}

Key words: Lake Taihu; lake area; dynamic change; RS; reclamation

太湖是我国第三大淡水湖泊, 地处长江三角洲人口稠密区, 不仅是上海、苏州、无锡等大中城市的水源 地, 也是重要的旅游风景区和水产品生产基地, 同时在流域的防洪、水量调节方面起着举足轻重的作用, 对 于流域内经济发展和人民生活具有重大意义. 随着人口的增长和经济的发展, 由于自然和人为的原因, 太湖 面积逐年减少. 特别是由于人为原因, 原有湖泊水面被堤坝隔绝、围垦, 用于耕地、建设用地、养殖、临时工程 等目的, 或由于开山取石、筑坝建设等, 造成泥沙淤积, 形成湖滩地. 这种人为和自然的作用使湖体日益缩 小, 特别是湖泊围垦, 影响湖泊调节洪水的能力, 加剧湖区洪涝灾害的发生, 造成了湖泊生态环境与生物资 源破坏,对太湖水环境质量下降有一定的影响 ${ }^{[1]}$.

据调查和分析统计, 20 世纪 $50-70$ 年代太湖由于围湖种植和围湖养殖等, 太湖的湖泊面积共减少 $160.17 \mathrm{~km}^{2[2]}$.

遥感技术由于不受时间和空间的限制, 即实时性强、宏观性强、准确可靠的优点 ${ }^{[3]}$, 是进行湖泊动态变 化研究的一种行之有效的方法. 本文利用 80 年代后期以来不同时期的 LANDSAT 卫星遥感图像, 研究了太 湖面积的时空动态变化.

\section{1 数据收集与处理}

\section{1 数据源}

本文收集了 4 期美国陆地卫星 TM 遥感图像数据 (分辨率 $30 \times 30 \mathrm{~m}^{2}$ ), 以及 2 期 $\mathrm{ETM}$ 遥感图像数据 (分辨率 $15 \times 15 \mathrm{~m}^{2}$ ). 6 期数据的时间分别是 1988 年 11 月 3 日、1991 年 7 月 23 日、1994 年 6 月 29 日、1997

* 中国科学院知识创新项目 (KZCX3 - SW - 331) 资助. 2004-10-12 收稿;2004-11-18 收修改稿.

殷立琼,女, 1977 年生, 硕士;E-mail:lqyin2002@yahoo. com.cn. 
年 5 月 4 日、 2000 年 5 月 4 日、2002 年 7 月 13 日. 由于 1991 年 7 月 23 日正值太湖特大洪水期, 不作为本次 研究的本底数据. 而其他 5 个时期的水位基本处于平均水位左右, 因此, 本次研究选择这 5 期符合要求的数 据作为本底数据. 另外利用 2003 年 10 月份的航空遥感图像 (1:10000), 既作为研究太湖面积动态变化的最 新一期遥感数据源, 又作为 TM(ETM)遥感数据解译的野外验证辅助信息源.

\section{2 遥感数据处理}

数据处理主要包括遥感图像精纠正和图像合成.

本研究使用了 20 张 1:50,000 地形图对 TM 和 ETM 图像进行几何精校正. 为了保证面积的准确, 这里 选择了 ALBERS(等积) 投影; 通过选取 20 个以上均匀分布又清晰可辨的控制点, 如河与河的交叉、路与河 的交叉或其他可选取的具有明显特征的永久地物,保证图像几何精纠正精度控制在 0.3 个象元范围内.

对 TM 和 ETM 图像数据, 采用了 $5 、 4 、 3$ 的模拟真彩色合成方案, 即与实际地物有着相类似的颜色, 如水 为蓝色、山林为绿色等, 以利于围居类型的解译与提取. ETM 图像比 TM 图像多一个 $15 \mathrm{~m}$ 分辨率的 8 波段, 通过 8 波段与 $5 、 4 、 3$ 波段的数据融合, 可最终获得分辨率为 $15 \mathrm{~m}$ 的模拟真彩色遥感图像 (图 1 ).

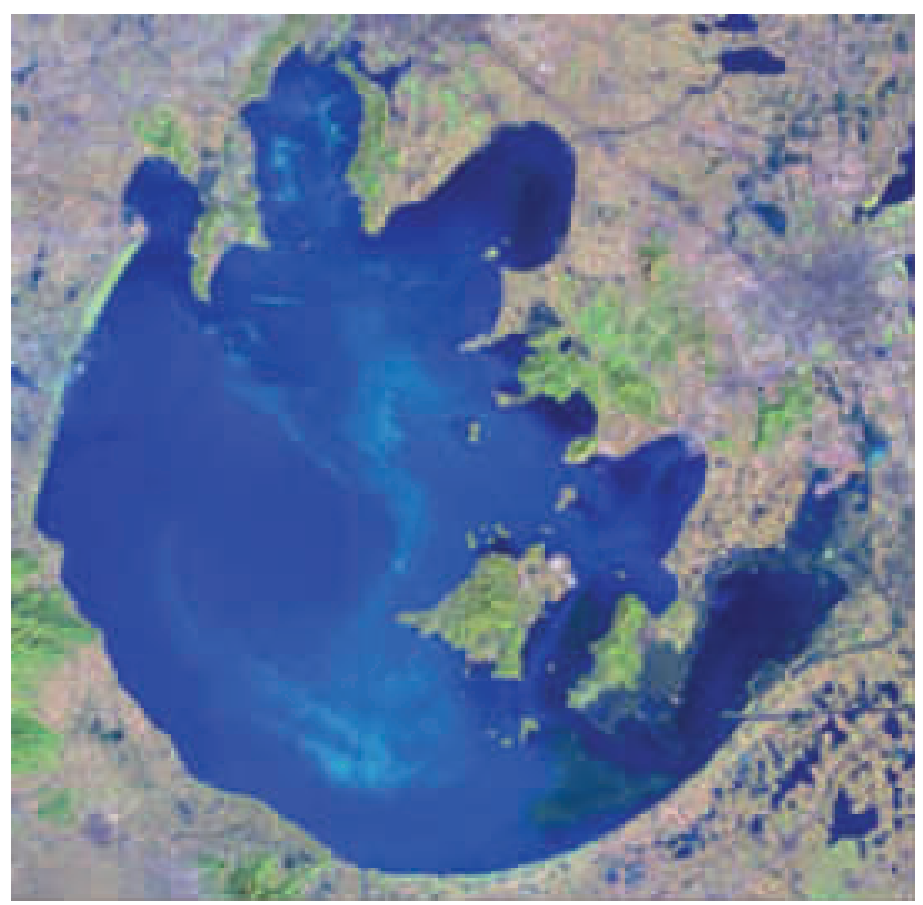

图 1 太湖遥感图像

Fig. 1 RS Image of Taihu Lake

\section{2 湖泊动态变化类型的判读与解译}

\section{1 湖泊动态变化类型判读标志建立}

湖泊动态变化类型是指使湖泊水面减少的湖泊围屋、滩地、取土围堰等用地类型.

携带合成的 TM543 模拟真彩色卫星影像和航片, 选取太湖重点地区做实地调查, 将 TM 图像上的每一 个动态变化图斑与实际地块建立一一对应关系, 根据图斑的形状、色调、纹理结合地理位置、大小等因素建 立解译判读标志. 取土围堰一般面积较大, 比较容易判读, 这里主要是湖泊围垦和湖滩地的判读标志 (表 1). 
表 1 TM (ETM) 图像湖泊动态变化类型解译标志

Tab. 1 Interpretation signals of reclaimed types of TM(ETM) images

\begin{tabular}{cccc}
\hline 类 型 & 色 调 & 纹 理 & 形状 \\
\hline 鱼塘 & 深蓝色 & 较均一 & 较规则 \\
滩地 & 蓝绿色 & 不均一 & 不规则 \\
耕地 & 绿色 & 较均一 & 较规则 \\
其他建设用地 & 品红色 & 较均一 & 较规则 \\
林地 & 绿色 & 不均一 & 不规则 \\
\hline
\end{tabular}

\section{2 湖泊动态变化图斑勾绘}

在 Erdas8. 6 的支持下,采用人机交互方式, 依次勾绘出 1988、1994、1997、2000、2002 和 2003 年遥感图 像上的太湖边界, 获取不同时间段太湖面积, 再勾绘出不同时期的湖泊动态变化图斑. 根据 TM 图像湖泊动 态变化类型解译标志, 解译其围星利用类型、滩地和取土围堰, 得到矢量图层. 利用 Arc/Info 软件对不同时 期的太湖湖泊动态变化矢量图层 (图 2) 进行图形编辑、加工等, 再利用 Excel 统计不同时期的太湖减少面积 和各动态变化类型的面积. 其结果见表 2.

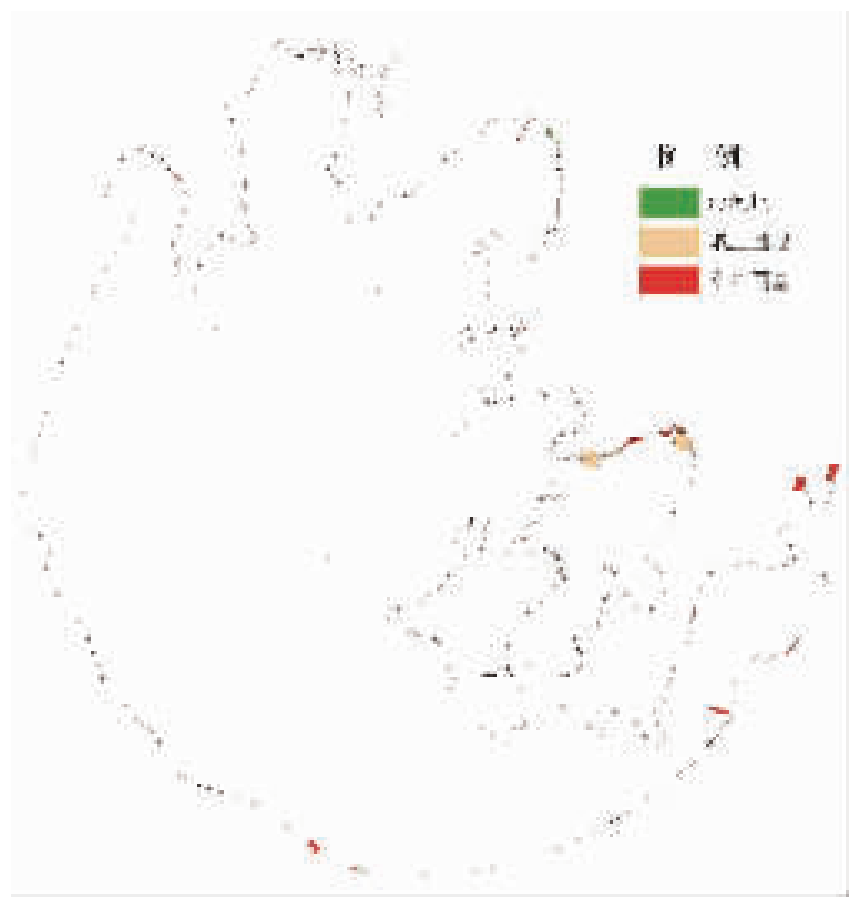

图 2 太湖湖泊动态变化类型图

Fig. 2 Classification of dynamic change of Lake Taihu

\section{3 结果分析}

太湖近 15 年来湖体面积不断减少, 由 1988 年的 $2345.0165 \mathrm{~km}^{2}$ 减少到 2003 年的 $2335.9939 \mathrm{~km}^{2}$. 面积 减少的原因,一是由于原有湖泊水面被堤坝隔绝或围屋用于耕地、建设用地、养殖等目的而使湖泊可交换水 体面积减少的围垦行为; 二是缘于开山取石、丁坝建设等原因, 造成泥沙淤积, 形成湖滩地, 使湖泊水面减 少; 另外, 临时性的取土围堰工程也使湖泊短期内面积减少.

由表 2 可以看出, 从 1988 年到 2003 年, 太湖湖泊面积减少 $9.0226 \mathrm{~km}^{2}$, 其中围垦用于鱼塘、耕地、林地 
和建设用地的面积 $4.4584 \mathrm{~km}^{2}$, 由于开山取石等缘由造成泥沙淤积而形成的湖滩地面积 $0.6968 \mathrm{~km}^{2}$, 临时 用于取土工程的围堰面积 $3.8674 \mathrm{~km}^{2}$. 在 $4.4584 \mathrm{~km}^{2}$ 湖泊围垦面积中, 用作鱼塘 $3.3386 \mathrm{~km}^{2}$, 占湖泊围垦面 积的 $74.88 \%$; 建设用地 $1.0575 \mathrm{~km}^{2}$, 占湖泊围垦面积的 $23.72 \%$; 耕地 $0.0421 \mathrm{~km}^{2}$, 占湖泊围叚面积的 $0.95 \%$; 林地面积 $0.0202 \mathrm{~km}^{2}$, 占湖泊围层面积的 $0.45 \%$.

由表 2 同时可以看出,近 15 年来,太湖湖泊围垦有下降的趋势, 2000 年之前,湖泊水面减少的主要原因 是湖泊围垦;2000 年后由于临时性的工程取土围堰使湖泊水面暂时性地减少,围垦面积有较大幅度减少, 但仍然没有杜绝. 由此看出, 进入 21 世纪, 太湖形势依然严峻, 必须尽快制定太湖管理条例, 严格保护水环 境,杜绝类似围湖造地、取土围堰这种破坏生态环境的行为.

表 2 太湖湖泊面积动态变化统计 $\left(\mathrm{km}^{2}\right)$ *

Tab. 2 The statistics of area dynamic change in Taihu Lake $\left(\mathrm{km}^{2}\right)$

\begin{tabular}{|c|c|c|c|c|c|c|c|}
\hline 土地利用类型 & 1988 & $1988-1994$ & $1994-1997$ & $1997-2000$ & $2000-2002$ & $2002-2003$ & 小计 \\
\hline 鱼塘 & & 0.9145 & 1.4340 & 0.9474 & 0.0427 & & 3.3386 \\
\hline 耕地 & & 0.0421 & & & & & 0.0421 \\
\hline $\begin{array}{l}\text { 建设 } \\
\text { 用地 }\end{array}$ & & 0.5344 & 0.3191 & $\begin{array}{c}0.0792 \\
-0.4269\end{array}$ & 0.0674 & 0.4843 & 1.0575 \\
\hline 林地 & & & 0.0202 & & & & 0.0202 \\
\hline 取土围堰 & & & & & 1.7361 & 2.1313 & 3.8674 \\
\hline 围湖造地面积 & & 1.4910 & 1.7733 & 0.5997 & 0.1101 & 0.4843 & 4. 4584 \\
\hline 湖滩地 & & 0.1960 & 0.1722 & 0.3062 & 0.0224 & & 0.6968 \\
\hline 湖泊减少面积 & & 1.6870 & 1.9455 & 0.9059 & 1.8686 & 2.6156 & 9.0226 \\
\hline 湖泊面积 & 2345.0165 & 2343.3295 & 2341.3840 & 2340.4781 & 2338.6095 & 2335.9939 & \\
\hline
\end{tabular}

* 2000 年时有一块面积为 $0.4269 \mathrm{~km}^{2}$ 的建设用地退地还湖.

\section{4 参考文献}

１1］张振克. 太湖流域湖泊水环境问题、成因与对策. 长江流域资源与环境, 1999,8 (1).

[2] 中国科学院南京地理湖泊研究所. 太湖流域自然资源地图集. 北京: 科学出版社, 1991 .

[3] 王建武, 肖红生,杨燕琼. 应用卫星遥感影像分析粤西沿海围层动态变化. 华南农业大学学报,2000,21(1).

[4] 刘 庄,蒋建国,沈渭寿等. 太湖流域湖泊滩地资源及其开发利用. 农村生态环境,2003,19(4):27-30. 